\title{
Major Facilities
}

\author{
Plenary speaker Dean Eastman \\ Reports on NRC study of materials' needs
}

The Plenary Session will feature Dean Eastman, co-chairman of the Major Materials Facilities Committee of the National Academy of Sciences' National Research Council. He will deliver a major report on the committee's conclusions and recommendations regarding priorities for new and upgraded major materials research facilities. The Chairman of the Plenary Session, MRS Vice President Bill Appleton, reports:

\section{MRS Participation}

"Those who attended the 1983 Plenary Session will recall that George Keyworth, Presidential Science Advisor and Director of the Office of Science and Technology, stressed to our members the need for the materials science community to establish a representative voice which could assist in evaluating materials research and in setting national priorities. As a result, Keyworth's office asked the National Research Council of the National Academy of Sciences to assist in establishing priorities for major facilities-i.e., those with initial costs of at least $\$ 5$ million-for materials research.

"A committee of 22 members was formed within the NRC Commission of Physical Science, Mathematics, and Resources.

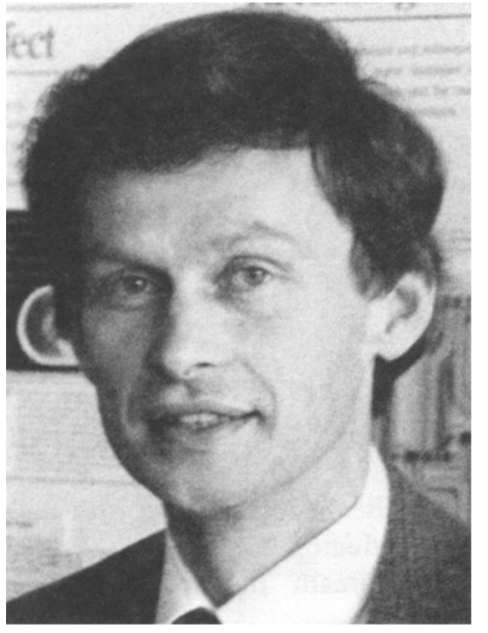

DEAN EASTMAN
Dean Eastman of International Business Machines Corporation and Professor Frederick Seitz of Rockefeller University were asked to serve as co-chairmen. The committee's membership was broadly reflective of the diverse disciplines that use such major facilities, such as synchrotron radiation and neutron facilities, and includes the following:

Richard B. Bernstein, University of California, Los Angeles

Robert J. Birgeneau, Massachusetts Institute of Technology

Jerome B. Cohen, Northwestern University

Mildred S. Dresselhaus, Massachusetts Institute of Technology

Harry G. Drickamer, University of Illinois

Peter Eisenberger, Exxon Research and Engineering Company

Donald Engelman, Yale University

Walter Kohn, Institute of Theoretical Physics, Santa Barbara

David W. Lynch, Iowa State University and Ames Laboratory

Albert Narath, AT\&T Bell Laboratories

William D. Nix, Stanford University

Edward Rubenstein, Stanford University Medical Center

John J. Rish, National Bureau of Standards

Albert I. Schindler, Naval Research Laboratory

Arthur Sleight, E.I. du Pont de Nemours \& Company, Inc.

William P. Slichter, AT\&T Bell Laboratories

Joseph V. Smith, University of Chicago

Richard Stein, University of Massachusetts

H. Guyford Stever, Universities Research Association

John M. White, University of Texas, Austin

Top Priority: Synchrotron Facility

"The committee's report, entitled Major Facilities for Materials Research and Related Disciplines, was transmitted to Keyworth's office this summer. The report presents priorities both for new facilities and for new capabilities at existing facilities. The top priority assigned for a new facility was a $6 \mathrm{GeV}$ synchrotron radiation facility. The top priority for new capabilities at an

[Continued on Page 30]

\section{NSF seeks help}

The National Science Foundation is conducting an evaluation of the impact of the Foundation's funding support on recent advances in the fundamental engineering sciences. One of the disciplines in the engineering sciences being evaluated is "materials science engineering," and the NSF has asked the Materials Research Society to aid in this part of the evaluation. F.W. Young of Oak Ridge National Laboratories is managing this task for the Society.

The MRS is asked to identify topical areas within materials science engineering that have advanced substantially over the past twenty years, and for each topical area the seminal papers that led this advancement. The National Science Foundation can then identify the funding source for the work described in these papers and complete the evaluation. Some thirty distinguished materials scientists, distributed over the broad field of materials science have been asked to participate in this task.

The continuing need for evaluation of the effectiveness of the mechanisms for support of scientific research in the United States is apparent. It is important that the Materials Research Society assume its proper position in this process by providing timely, well-reasoned information and advice on matters pertaining to materials science. 


\title{
MRS-Who are we?
}

\author{
Members encouraged to participate \\ to help broaden the Society's scope.
}

When we look back over the past seven or eight years of MRS activities and recall who have been the volunteers devoting their time and talents to the Society, we see a very distinct pattern. As soon as the Society's events grew to the point where significant resources were required to support them, volunteers from major industrial and government labs entered the picture in a major way. Why and how did this come about?

In the early days, the MRS had virtually no resources of its own. The myriad costs of running a meeting including a growing number of symposia could neither be covered by reasonable registration fees alone nor with the addition of government grants to individual symposia. These sources of revenue did and do fulfill a vital role, but without significant dues income and with no fulltime staff or dedicated headquarters, additional support was indispensible.

\section{The Costs of 'Free' Labor}

This support came in the form of "free" labor by scientists who ran symposia, ran complete meetings, were members of and chaired committees and served as officers of the Society. (In fact those who assumed the role of meeting chair, the "hot seat" of Society jobs, became so familiar with and so strongly influenced the Society, that they were quickly catapulted into officer positions.) But was their labor really free? To the Society, indeed it was. But to the home institution of these scientists it was certainly not. It was clearly for this reason that the volunteers came primarily from large research and development laboratories which could afford to contribute both the time of their researchers and other resources, such as secretarial support. It was, however, not merely size that determined our volunteers' origins. The research management in these labs had to have had a farsighted recognition of the benefits to be accrued by their staff involvement in Society activities. They determined that a healthy MRS would enhance their own materials research programs through scientific interchanges both at meetings and through individual contacts, and that their laboratories could strongly influence the program topics treated by the MRS. Our volunteers were therefore encouraged to participate as a legitimate part of their professional endeavors.

Because of this backbone of large-lab support, it was also possible to benefit from the involvement of the university community of materials scientists who, with limited research grants, would otherwise have been hard-pressed to participate.

\section{A Broadening Leadership Base}

As a leader of the MRS, one sometimes hears concerns about a lack of diversity of institutions from which MRS leaders are drawn. In fact, without examining the underlying reasons for this, the leadership seems "inbred." To some extent, of course, the greater familiarity that current volunteers have with colleagues at their home institution does influence who may be asked to help with future chores. But for the most part, we have found that, notwithstanding a true diversity in the institutions of those asked to volunteer, the positive responses seem primarily to come from those with strong institutional support.
Will this trend continue? Probably not. At present the majority of officers and committee chairs, as in the past, are either now, or were at the time they began their involvement, from a very few well-known laboratories. But the internal resources of the MRS are gradually growing. With an expanding dues-paying membership and with new revenue-generating activities (such as book publication and equipment exhibits), the base will soon exist to buttress the activities of volunteers who bring their expertise but cannot contribute institutional resourses nor contribute the inordinate amount of time that is currently required.

The MRS has greatly benefitted from the forward-thinking involvement of the larger research laboratories and their people and we fully hope and expect to continue this healthy collaborative relationship. At the same time, we will undoubtedly see greater numbers of new faces in our ranks playing crucial roles for the Society and representing a wider variety of institutions. In fact, the primary purpose for putting these thoughts in the BULLETIN is to encourage all of our members and meeting participants to consider where it is that they might want to influence the Society's activities and to contact any officer, councilor, committee chair or the headquarters indicating their willingness to become involved.

\section{ELTON KAUFMANN}

\section{Address Update}

You will soon be receiving a copy of the 1984 MRS Membership Directory. Please check to be sure your address and telephone number are correct.

To update this information, complete the card in the back of the Directory and return it promptly to:
Materials Research Society
9800 McKnight Road, Suite 327
Pittsburgh, PA 15237 